Studer, R.; Danuser, B.; Hildebrandt, H.; Arial, M.; Gomez, P. Hyperventilation complaints in music performance anxiety among classical music students. Journal of Psychosomatic Research, 70(6):557-564, 2011.

\begin{tabular}{|l|l|}
\hline Postprint version & Final draft post-refereeing \\
\hline Journal website & $\underline{\text { http://www.sciencedirect.com/science/journal/00223999 }}$ \\
\hline Pubmed link & http://www.ncbi.nlm.nih.gov/pubmed/21624579 \\
\hline DOI & $\underline{10.1016 / \text { j.jpsychores.2010.11.004 }}$ \\
\hline
\end{tabular}




\section{Hyperventilation Complaints in Music Performance Anxiety among Classical Music Students}

Short running head: Hyperventilation in MPA

Name of department: Institute for Work and Health, Lausanne, Switzerland

Regina Studer, lic. phil., Brigitta Danuser, Prof., Horst Hildebrandt, Prof., Marc Arial, PhD and Patrick Gomez, PhD

Corresponding author:

Regina Studer

Rue du Bugnon 21

$\mathrm{CH}$ - 1011 Lausanne

Switzerland

Phone: $\quad 0041213147618$

Fax: $\quad 0041213147420$

Mail:_ regina.studer@hospvd.ch 


\begin{abstract}
Objective: Despite the importance of respiration and hyperventilation in anxiety disorders, research on breathing disturbances associated with hyperventilation is rare in the field of music performance anxiety (MPA, also known as stage fright). The only comparable study in this area reported a positive correlation between negative feelings of MPA and hyperventilation complaints during performance. The goals of this study were a) to extend these previous findings to the period before performance, b) to test whether a positive correlation also exists between hyperventilation complaints and the experience of stage fright as a problem, c) to investigate instrument-specific symptom reporting, and d) to confirm gender differences in negative feelings of MPA and hyperventilation complaints reported in other studies.
\end{abstract}

Methods: We assessed 169 university students of classical music with a questionnaire comprising: the State-Trait Anxiety Inventory for negative feelings of MPA; the Nijmegen Questionnaire for hyperventilation complaints; and a single-item for the experience of stage fright as a problem.

Results: We found a significant positive correlation between hyperventilation complaints and negative feelings of MPA before performance, and a significant positive correlation between hyperventilation complaints and the experience of stage fright as a problem. Wind musicians/singers reported a significantly higher frequency of respiratory symptoms than other musicians. Furthermore, women scored significantly higher on hyperventilation complaints and negative feelings of MPA.

Conclusion: These results further the findings of previous reports by suggesting that breathing disturbances associated with hyperventilation may play a role in MPA prior to going on stage. Experimental studies are needed to confirm whether hyperventilation complaints associated with negative feelings of MPA manifest themselves at the physiological level.

Keywords: breathing; hyperventilation; musicians; performance anxiety; stage fright 


\section{Introduction}

Performance anxiety is a widespread phenomenon affecting individuals across a range of activities, such as public speaking, sport, and performing arts like dancing, acting, and music. Music performance anxiety (MPA - also referred to as stage fright) is experienced by a high percentage of professional musicians and music students (1). A large survey of 2,212 professional orchestra musicians showed that $24 \%$ of them experienced stage fright as a problem and $16 \%$ as a severe problem (2). Stage fright was the leading severe problem amongst the musicians surveyed.

A standardized definition of MPA is still lacking. There is a consensus that performance anxiety in musicians is characterized by noticeable apprehension about performing, which may or may not impair the quality of the performance (3-6). Recently, Kenny (4) defined MPA as "the experience of marked and persistent anxious apprehension related to musical performance (...), which is manifested through combinations of affective, cognitive, somatic and behavioral symptoms". The present article concentrates on the affective component of MPA and on self-perceived somatic symptoms, in particular on self-perceived hyperventilation complaints.

There is evidence in the literature that MPA might be associated with hyperventilation. Performance-anxious musicians have been reported to experience symptoms such as palpitations, perspiration, a dry mouth, trembling and disturbances in their breathing patterns before and/or during performance (7-10). Amongst others, these symptoms often occur during hyperventilation problems. Hyperventilation is defined as breathing in excess of metabolic requirements. Overbreathing leads to a drop in the partial pressure of arterial $\mathrm{CO}_{2}$ (hypocapnia) and a rise in the blood $\mathrm{pH}$ level (respiratory alkalosis), which can cause cerebral and peripheral vasoconstriction and thereby a deficiency in oxygen supply. Acute 
hyperventilation also increases neuronal excitability, leading to paresthesia, muscle cramps or even tetany (11). Some of the physiological symptoms reported by performance-anxious musicians, whether they are respiratory (e.g. shortness of breath), central (e.g. being confused) or peripheral (e.g. cold hands), may thus be explained by the metabolic changes induced by overbreathing.

However, although hyperventilation has been mentioned occasionally as a manifestation of anxiety during musical performance $(5 ; 8)$, little attention has been paid to the association between MPA and hyperventilation. This is surprising considering that respiratory symptoms, such as shortness of breath, rank high among the symptoms experienced by musicians during performance (9), and given the association between respiration and emotion (12) and more specifically anxiety disorders (13), as well as between hyperventilation and anxiety disorders (14).

To our knowledge, only one study has thus far investigated the association between the negative feelings of $\mathrm{MPA}^{1}$ and hyperventilation complaints (15). In a questionnaire survey, these authors found a high positive correlation $(r=.71)$ between negative feelings of MPA, assessed with the state scale of the Spielberger State-Trait Anxiety Inventory (16), and hyperventilation complaints, assessed with the Nijmegen Questionnaire (NQ) $(17 ; 18)$, during performance. The study by Widmer et al. (15) further showed that women scored significantly higher than men in MPA and in hyperventilation complaints, and that on the basis of the NQ they were three times more likely than men to be classified as hyperventilators during performance. These findings are in line with other studies showing that women score consistently higher than men in MPA $(2 ; 15 ; 19)$ and in hyperventilation complaints/proneness $(14 ; 15 ; 20 ; 21)$.

\footnotetext{
${ }^{1}$ When referring to the negative affective component of MPA, we will use the term "negative feelings of MPA" throughout the article.
} 
No study has yet investigated the association between negative feelings of MPA and hyperventilation complaints before performance. The investigation of the pre-performance period is particularly important given that many musicians report that their apprehensions are greatest prior to the performance rather than during the performance itself (5).

Although the affective symptoms are central to the experience of MPA, high levels of anxiety do not automatically imply that stage fright is perceived as a problem. We were able to show that there is only a moderate association between the degree of anxiety experienced and the degree to which stage fright is perceived as a problem (22). Furthermore, no study has yet investigated the association between hyperventilation complaints and the experience of stage fright as a problem. Stage fright may be considered as a problem, particularly when its (physiological) manifestations negatively influence the ability to perform. Since physiological symptoms associated with hyperventilation (e.g., cold hands, stiffness in fingers, difficulty breathing deeply) can impair a musician's ability to perform, it is particularly important to investigate the association between the subjective physiological complaints indicative of hyperventilation and the experience of stage fright as a problem.

Finally, little is known about instrument-specific symptom reporting. Wolfe (10) has provided evidence for instrument dependent differences in the experience of some physiological symptoms, however, without focussing on respiratory symptoms. Due to the particular importance of respiration for wind musicians and singers, these musicians might be particularly affected by hyperventilation complaints, especially by the respiratory symptoms. The purpose of the present study was to extend knowledge about the possible role of breathing disturbances associated with hyperventilation in MPA. Specifically, we aimed to extend previous findings by Widmer et al. (15) in two important ways. First, whereas Widmer et al. (15) assessed the association between hyperventilation complaints and negative feelings of MPA during performance, we assessed this association before performance. We 
hypothesized that the more musicians score high in negative feelings of MPA before performance, the more hyperventilation complaints they report (hypothesis 1). Second, we tested whether there is a positive association between hyperventilation complaints and the experience of stage fright as a problem. We hypothesized that the more stage fright is perceived as a problem, the more hyperventilation complaints are experienced (hypothesis 2). Furthermore, we hypothesized that wind musicians and singers score higher on the NQ than other musicians, particularly on its respiratory subscale (hypothesis 3). Finally, to confirm findings from previous research, we also investigated whether women score higher than men in hyperventilation complaints and in negative feelings of MPA (hypothesis 4). 


\section{Methods}

\subsection{Sample and Procedure}

In spring 2007, all the students in four of Switzerland's French-speaking music universities $(n=870)$ were contacted by mail and asked to participate in a questionnaire survey on the topic of music performance. The questionnaire was returned by 195 students (a $22 \%$ response rate). This response rate is in the same range as other large studies using mailed questionnaires as a recruitment strategy $(23 ; 24)$, Five students for whom playing an instrument or singing was not the core element of their studies (e.g. students of conducting or of teaching the theoretical aspects of music) were excluded from the sample. A further 21 students had to be excluded because of incomplete data.

The final sample consisted of 169 students ( $61 \%$ female) from the classical music section. Participants' age ranged from 15 to 45 years old, with a mean of 24.3 years $(S D=4.3)$. There were 23 vocalists (14\%), 31 brass players (18\%), 14 woodwind players (8\%), 54 string players (32\%), 33 pianists (20\%) and 14 miscellaneous musicians (8\%). The students ranged between the first and seventh year of their professional music education at university, with $75 \%$ in the first three years.

\subsection{Questionnaire}

The questionnaire assessed demographic information (gender and age) and academic information concerning the different aspects of their musical training and their instrument. The students were asked to list their recent public solo performances. Since the purpose of this study was to investigate MPA and not test-anxiety, participants were instructed not to take into account examinations or selection contests, but to exclusively list performances outside a test context. All musicians mentioned at least one solo performance, 18 mentioned 
exactly one. The focus on solo performances was chosen because they have been repeatedly reported to generate higher levels of MPA than ensemble performances $(25 ; 26)$. A solo performance was defined as a performance of a composition or a passage for an individual voice or instrument, with or without accompaniment.

For the hyperventilation complaints scale and the negative feelings of MPA scale, the students were asked to indicate which hyperventilation complaints and negative feelings they had experienced just before the concerts they mentioned in the list of their recent public solo performances.

- Hyperventilation complaints: Hyperventilation complaints were assessed with the Nijmegen Questionnaire (NQ) $(17 ; 18)$. This consists of 16 symptoms known to often cooccur during hyperventilation problems (e.g. shortness of breath, vertigo). The questionnaire has shown its ability to discriminate between patients diagnosed with hyperventilation syndrome and patients suspected to suffer from other respiratory problems (18). It also has been shown to correctly classify controls and patients diagnosed with hyperventilation syndrome at $93 \%$ (17). Each item has to be rated on a 5-point rating scale (0 "never" to 4 "very often") indicating the frequency of the physiological symptoms. The final score can vary between 0 , indicating no symptoms, to 64 , indicating a very high frequency of all symptoms. A threshold of 22-23 points is habitually used to separate hyperventilators from non-hyperventilators $(15 ; 18 ; 27 ; 28)$.

- Negative feelings of MPA: The negative feelings of MPA were assessed with the French version (29) of the state scale of the State-Trait Anxiety Inventory ${ }^{2}$ (16). This questionnaire has been often used to assess the negative feelings of MPA (15;30-32) and has been shown to have good psychometric properties. The internal consistency reliability

\footnotetext{
${ }^{2}$ When referring to the state scale of the Spielberger State-Trait Anxiety Inventory the term «STAI-S» will be used in the following for reasons of readability. The correct abbreviation is «STAI form Y-A».
} 
estimated by Cronbach's alpha was shown to be higher than .90 (16). The questionnaire consists of 20 items addressing apprehensive feelings of anxiety. Each item has to be rated on a 4-point scale (1 "not at all" to 4 "very much so"). The total score can vary between 20 , indicating no anxiety at all, to 80 , indicating extreme anxiety. For the purpose of our study, we adapted the instructions to music performance situations as done in other studies $(15 ; 32)$. Further, we changed the verb tense from the present to the past, because we wanted to assess how the students felt before their recent public solo performances.

- Experience of stage fright as a problem: One item asked the students to evaluate whether they perceived stage fright as a problem on a 5-point rating scale (anchored by 0 "stage fright is not a problem for me", and 4 "stage fright is a major problem for me"). Since the word "stage fright" is more commonly used and understood in the everyday speech, "stage fright" was used for this item rather than the more technical term "MPA". The same item has been used by Fishbein et al. (2) and Steptoe et al. (33) in order to assess stage fright as a problem.

The questionnaire included further items on the consequences of stage fright, the need for information and support, and the use, knowledge and acceptance of coping strategies (22).

\subsection{Data Reduction and Data Analysis}

All statistical analyses were performed with STATA11 (Stata Statistical Software, StataCorp LP, Texas). We calculated the sum score of the STAI-S and the NQ for each student. With reference to the STAI manual (34), a student's missing values on the STAI-S were replaced by his/her mean of the completed items and rounded up to the next whole number (if not more than $10 \%$ of his/her values were missing). If more than $10 \%$ of responses were missing, then the questionnaire was eliminated from consideration. Missing values in the NQ were treated in the same way. 
To test the first hypothesis, on the positive association between the NQ score and the STAI-S score before performance, we calculated the Pearson correlation between these two measures. To test the second hypothesis, on the positive association between the NQ score and the experience of stage fright as a problem, we calculated the Pearson correlation between the NQ and the scores of the experience of stage fright as a problem. Since Widmer et al. (15) reported a consistently higher correlation between the STAI-S and the NQ for women than for men, the correlation analyses were carried out for men and women separately.

The third hypothesis, on the higher scores of wind musicians / singers on the NQ and on its subscales (respiratory and non-respiratory), was tested by three one-tailed t-tests. The respiratory subscale was composed by four items, i.e., tightness in the chest, difficulty breathing deeply, shortness of breath, fast or deep breathing, based on van Dixhoorn and Duidenvoorden (17). The non-respiratory subscale was composed by the twelve remaining items.

The fourth hypothesis, on gender differences in the NQ and STAI-S scores, was tested by two one-tailed t-tests. We further assessed gender differences for the experience of stage fright as a problem. Since the experience of stage fright as a problem is an ordinal measure, gender differences in this variable were tested using a Chi2 test. A significance level of .05 was set for all statistical tests.

Finally, to compare the percentage of hyperventilators in our sample with the percentage reported by Widmer et al. (15), we applied the same classification criterion as these authors, i.e., non-hyperventilators (0-22 points on the NQ) and hyperventilators (23-64 points on the NQ). 


\section{Results}

Descriptive results for the NQ and its subscales, the STAI-S, and the experience of stage fright as a problem scores are shown in Table 1. The descriptive results for the NQ and the STAI-S for the sample of Widmer et al. (15) are shown in the same table. The means and variances of the STAI-S and the NQ for our sample and Widmer et al.'s (1997) proved to be very similar. In our sample, the negative feelings of MPA, assessed with the STAI-S, varied from very low to very high scores and, thus, covered almost the total range of possible scores. The hyperventilation complaints score, assessed with the NQ, ranged from the lowest possible score to 47 . Given that the NQ score can reach a maximum score of 64 , there were no students with extremely high hyperventilation complaints in our sample ${ }^{3}$.

Women had significantly higher STAI-S scores than men $(t(167)=2.08 ; p=.02)$. Women also scored significantly higher in the NQ than men $(t(167)=3.93 ; p<.001)$. There was no significant difference between men and women in the experience of stage fright as a problem $\left(\chi^{2}(4, N=169)=7.04, p=.13\right)$. Whereas wind musicians / singers did not score significantly higher on the complete NQ than the other musicians $(t(167)=0.02 ; p=.49)$, they had significantly higher scores on the respiratory subscale than the other musicians $(t(164)=2.33$; $p=.01)$. The scores on the non-respiratory subscale were not higher in the wind musicians / singers than in the other musicians $(t(166)=-1.48 ; p=.93)$. Furthermore, the two instrument groups were not different from each other with respect to their STAI-S score $(t(167)=-1.31$; $p=.19)$ and the experience of stage fright as a problem $\left(\chi^{2}(4, N=169)=1.51, p=.83\right)$.

Based on the classification criterion used by Widmer et al. (15) - i.e., 0-22 points on the NQ: non-hyperventilators; $23-64$ points on the NQ: hyperventilators $-37.3 \%$ of the students surveyed were classified as pre-performance hyperventilators. Among the female students,

\footnotetext{
${ }^{3}$ Since the NQ assesses the frequency of hyperventilation complaints, the interpretation of the scores for musicians indicating only one public solo performance is difficult. However, the exclusion of these musicians $(n=18)$ from the analyses did not change the results. We therefore report the results for the whole sample.
} 
$48.5 \%$ were classified as hyperventilators before performance vs. $19.7 \%$ of the male students. Thus, female students were 2.5 times more likely to be classified as hyperventilators before performance than their male counterparts.

The correlations between the NQ and the STAI-S and between the NQ and the experience of stage fright as a problem are shown in Table 2. The correlation between the NQ and the STAI-S was positive and significant. Compared to the $r$ of the entire sample, the correlation was slightly lower for women and slightly higher for men. Widmer et al. (15) reported a similar correlation for men, yet a much higher correlation for women. The scatter plot of the NQ and the STAI-S scores is depicted in Figure 1. The correlation between the NQ and the experience of stage fright as a problem was likewise positive and significant. The correlation for women and men were identical. The scatter plot of the NQ and the experience of stage fright as a problem scores is depicted in Figure 2.

In order to explore whether instrument-specific differences are also manifested in the correlation analyses, we calculated the correlations between (a) the NQ and the STAI-S, (b) the two subscales of the NQ and the STAI-S, (c) the NQ and the experience of stage fright as a problem, and (d) the two subscales of the NQ and the experience of stage fright as a problem for wind musicians / singers and the other musicians separately. The results are given in Table 3. All correlations were significant $(p<.05)$. The correlations between the nonrespiratory subscale of the NQ with both the STAI-S and the experience of stage fright as a problem were comparable between wind musicians / singers and the other musicians. The correlations between the respiratory subscale of the NQ with both the STAI-S and the experience of stage fright as a problem were somewhat lower in wind musicians / singers compared to the other musicians. The correlations between the total score of the NQ with both the STAI-S and the experience of stage fright as a problem were also slightly lower in wind musicians / singers compared to the other musicians. 


\section{Discussion}

As an extension to the study by Widmer et al. (15), which focused on hyperventilation complaints and negative feelings of MPA during performance, we investigated them before performance, since many musicians seem to reach peak anxiety before performance rather than during it (5). Correlation analyses showed a significant positive association between the Nijmegen Questionnaire (NQ) score and the state scale score of the Spielberger State-Trait Anxiety Inventory (STAI-S). Thus, an increase in feelings of MPA goes along with an increase in perceived physiological symptoms that are known to be associated with hyperventilation. Therefore, the first hypothesis on the positive association between hyperventilation complaints and negative feelings of MPA before performance could be confirmed. However, the association between the NQ and the STAI-S in our sample was lower than the one reported by Widmer et al. (15). Importantly, this difference is mainly due to gender. Whereas the correlations between the NQ and the STAI-S for men are similar in our study and Widmer et al.'s (15), these authors reported a surprisingly stronger correlation for women than we did for our female sample. It is unclear why there is such a large gender difference. One possible explanation for this finding is that negative feelings of MPA and hyperventilation complaints may indeed be correlated more strongly in women than in men during performance. A second possible explanation is the presence of some highly performance-anxious female musicians with very strong hyperventilation complaints in the sample of Widmer et al. (15), which could have increased the correlation.

Furthermore, we found a positive significant association between the NQ and the experience of stage fright as a problem, thereby confirming the second hypothesis. The experience of physiological symptoms associated with hyperventilation, e.g. difficulty breathing or cold hands, may be perceived as potentially debilitating for an upcoming performance as they 
would disrupt a musicians' ability to perform optimally. Cold hands may negatively influence the ability to play a string instrument or breathing difficulties may adversely affect the ability of a singer or wind musician to perform. Whereas negative feelings of MPA may be annoying without having any direct influence on the quality of the performance, the physiological symptoms may directly impair the performance. Stage fright may thus be perceived as a problem through the disruptive effects of physiological symptoms. Therefore, the experience of stage fright as a problem may rather be the consequence of hyperventilation complaints than their cause. However, the present study does not allow us to conclude the causal relation between the NQ and the STAI-S or between the NQ and the experience of stage fright as a problem. It is possible that negative feelings of MPA cause hyperventilation complaints, but it is also possible that hyperventilation complaints increase negative feelings of MPA, with each complaint mutually amplifying the intensity of the other. The same holds for the association between NQ and the experience of stage fright as a problem. Furthermore, the amount of variance of the NQ, which was accounted for by the STAI-S and by the experience of stage fright as a problem, was modest. This implies that, although the STAI-S and the experience of stage fright as a problem explained a significant portion of the variance of the NQ, the major part remains to be explained by other factors.

Wind musicians / singers had significantly higher scores on the respiratory subscale of the NQ than other musicians. At first sight, this result may be considered as an argument in favor of tailored therapy. However, although wind musicians / singers reported respiratory symptoms more frequently than other musicians, the correlations between the respiratory subscale and both the STAI-S and the experience of stage fright as a problem were not stronger in wind musicians / singers than in other musicians. The greater frequency of respiratory symptoms in wind musicians and singers may be due to a particular, non anxiety dependent focus on the parts of the body that are particularly important for performance. 
The present results further showed that female students scored significantly higher on the STAI-S than men. This is in agreement with previous studies showing that women consistently score higher in MPA than men $(2 ; 15 ; 19)$. Our results also showed that female students scored significantly higher on the NQ than their male counterparts. This result confirms the findings of Widmer et al. (15) and is in accordance with previous findings looking at the general population, showing that females are more prone to report hyperventilation symptoms $(14 ; 20 ; 21)$. Thus, the third hypothesis, on the higher STAI-S scores and NQ scores in female students before performance was confirmed. There have been several proposed explanations for the gender differences in self-reported distress (35). First, women may truly experience more distress and more symptoms. Second, women may express their emotions and symptoms more freely than men (response bias view). Third, women may respond to stress with different emotions and symptoms from men, e.g., sadness, depression in women vs. anger or addictive behavior in men (gendered response view). Interestingly, despite the fact that women report more symptoms and a higher anxiety level, there were no gender differences in the experience of stage fright as a problem. It is possible that there are indeed no gender differences in the degree to which stage fright is perceived as a problem. However, the possibility that this result could be due to the assessment method should be kept in mind. The single item may not be sensitive enough to show gender differences. The present study further showed that based on their hyperventilation complaints, female students were 2.5 times more likely to be classified as hyperventilators. This finding is in accordance with Widmer et al. (15), showing that a clear majority of hyperventilators in performance was female, and that females were three times more likely to be classified as hyperventilators during performance.

Based on the standard criterion used to classify hyperventilators and non-hyperventilators, we found a comparable percentage of pre-performance hyperventilators as reported by Widmer et 
al. (15) during performance. More than one third of the students of the present sample were classified as hyperventilators. This percentage is astonishingly high and should be considered with caution. In fact, whereas the NQ is a valid instrument for investigating the frequency of self-perceived hyperventilation complaints (which was the main reason for its use in the present study), its convenience for the diagnosis of pathological hyperventilation and for classifying healthy persons without respiratory pathology should be reconsidered for several reasons. First, the NQ was initially created in order to assess the effect of a therapeutic treatment rather than to diagnose hyperventilation and classify patients. Despite this, the NQ has been widely used as a screening instrument (27). Second, the classification between nonhyperventilators and hyperventilators on the basis of the NQ score has its origins in a study undertaken by van Doorn \& Folgering (18). They reported that a cut-off point between a score of 22 or 23 yielded the lowest percentage of false classifications of persons with a hyperventilation syndrome diagnosis and those without such a diagnosis. However, the sample consisted of patients admitted to hospital for a physiological respiratory examination and patients of a psychiatric polyclinic. Thus, one has to be cautious when applying a cut-off point of 22-23 to a healthy population without further thought. Finally, Grossman and de Swart (36) drew attention to the fact that solely using a questionnaire to diagnose hyperventilation syndrome leads to consistent misclassifications of patients and controls. For all the above mentioned reasons, we suspect that the percentage of real hyperventilators is overestimated, both in our study and in Widmer et al.'s (15). However, the NQ gives valid information on the frequency of hyperventilation complaints and can serve as a good basis for further physiological investigation (37). Thus, physiological studies to confirm the occurrence of hyperventilation problems in MPA are needed. In a recent study of university music students, we measured the partial pressure of $\mathrm{CO}_{2}$ and other cardiorespiratory parameters to 
investigate the association between MPA and breathing patterns associated with hyperventilation before performance (Studer et al., manuscript submitted).

Finally, some possible limitations of the study should be mentioned. First, the response rate in the present sample was only $22 \%$. However, this is within the range of the response rates of other large studies using questionnaire mailing as a recruitment strategy $(23 ; 24 ; 38)$. Further, the distribution of the STAI-S was normal and covered almost the whole range of possible anxiety scores. The same holds for the experience of stage fright as a problem. Thus, students with very different performance anxiety levels were represented in the surveyed sample. Therefore, there was no bias in returned questionnaires due to the level of performance anxiety or its experience as a problem. Furthermore, in a previous manuscript (22), we have provided evidence that the present sample can be considered representative of the larger community of music students. Furthermore, since the main goal of the present study was to investigate correlations between variables, it seems improbable that the response rate negatively affected the correlation results. The second possible limitation is that the experience of stage fright as a problem was assessed with a single item. This may be a limitation in terms of the reliability in assessing the objective problem that stage fright causes in musicians. However, the rationale for using the single item was to assess whether the students subjectively experienced stage fright as a problem, following the same approach as previously reported by Fishbein et al. (2) and Steptoe et al. (33). Third, MPA, the experience of stage fright as a problem, and the hyperventilation complaints were assessed retrospectively. The responses may therefore be subject to a bias due to the fading memories. In order to limit this bias, we asked the students to recall their last public solo performances, to list them, and to reply to the questionnaire referring to these listed performances. Fourth, since asthma exacerbation is known to be related to stress, and since asthma and 
hyperventilation have similar symptoms, asthma should be screened for in a future study on hyperventilation and emotion.

In conclusion, we could show a positive correlation between hyperventilation complaints and negative feelings of MPA before performance. Thus, the positive correlation between hyperventilation complaints and negative feelings of MPA during performance, shown in a previous study, could be extended to the period before performance. Considering the fact that some symptoms occurring in MPA have a strong similarity to the physiological effects of overbreathing, and that there is a significant association between hyperventilation complaints and negative feelings of MPA before and during performance, there may be an underlying hyperventilation problem to MPA. Importantly, physiological symptoms associated with hyperventilation co-occurring in MPA can be highly debilitating in a profession where specialised respiration and high manual dexterity are of major importance and therefore become problematic. The positive correlation between hyperventilation complaints and the experience of stage fright as a problem adds additional weight to this view. The results of empirical studies, which might replicate these self-reported data on the physiological level, will further our knowledge on the association between MPA and breathing disturbances associated with hyperventilation. Since gender differences in hyperventilation complaints and negative feelings of MPA were confirmed in our study, particular attention should be paid to gender differences on the physiological level in the future. If the association between hyperventilation complaints in musicians and negative feelings of MPA can be confirmed at the physiological level, this finding will have important implications for the future treatment of MPA as well as for the quality of performance and for the wellbeing of professional musicians and music students. 


\section{Acknowledgements}

We are grateful to the Swiss National Science Foundation, which funded the present study (subsidy $\mathrm{N}^{\circ}$ 100013-112520), and to the Swiss University Centre for Music Physiology for the kind support. The authors wish to thank the music universities, Julia Maillefer and Christa Flückiger for their precious help in the development of the questionnaire and their assistance in gathering the research data. Further, we would like to thank Pascal Wild, $\mathrm{PhD}$, for his precious help in the statistical analyses. 


\section{Reference List}

(1) Kenny DT. Negative Emotions in Music Making; Performance Anxiety. In: Juslin PN, Sloboda JA, editors. Handbook of Music and Emotion: Theory, Research, Applications.Oxford, UK: Oxford University Press; 2008.

(2) Fishbein M, Middlestadt SE, Ottati V, Straus S, Ellis A. Medical Problems Among ICSOM Musicians: Overview of a National Survey. Medical Problems of Performing Artists 1988;(March):1-8.

(3) American Psychiatric Association. Diagnostic and Statistical Manual of Mental Disorders. 4th ed. Washington, DC: American Psychiatric Association; 1994.

(4) Kenny DT. Music Performance Anxiety. In: Williamon A, editor. International Handbook of Musicians' Health and Wellbeing.Oxford, UK: Oxford University Press; 2008.

(5) Salmon PG. A Psychological Perspective on Musical Performance Anxiety - A Review of the Literature. Medical Problems of Performing Artists 1990;5(1):2-11.

(6) Wilson GD. Performance Anxiety. In: Hargreaves DJ, North AC, editors. The social psychology of music.Oxford, UK: Oxford University Press; 1997. p. 229-48.

(7) Steptoe A. Negative Emotions in Music Making: The Problem of Performance Anxiety. In: Juslin PN, Sloboda JA, editors. Music and Emotion: Theory and Research.New York: Oxford University Press Inc.; 2001. p. 291-307.

(8) Steptoe A, Fidler H. Stage Fright in Orchestral Musicians - A Study of Cognitive and Behavioral Strategies in Performance Anxiety. British Journal of Psychology 1987;78:241-9.

(9) Wesner RB, Noyes R, Davis TL. The Occurrence of Performance Anxiety Among Musicians. Journal of Affective Disorders 1990;18(3):177-85.

(10) Wolfe ML. Correlates of Adaptive and Maladaptive Musical Performance Anxiety. Medical Problems of Performing Artists 1989;4(1):49-56.

(11) Gardner WN. The pathophysiology of hyperventilation disorders. Chest 1996;109(2):516-34.

(12) Boiten FA, Frijda NH, Wientjes CJE. Emotions and Respiratory Patterns - Review and Critical Analysis. International Journal of Psychophysiology 1994;17(2):103-28.

(13) Wilhelm FH, Alpers GW, Meuret AE, Roth WT. Respiratory pathophysiology of clinical anxiety outside the laboratory: Assessment of end-tidal pCO2, respiratory pattern variability, and transfer function RSA. In: Fahrenberg J, Myrtek M, editors. Progress in ambulatory assessment.Göttingen, Germany: Hogrefe; 2001. p. 313-43. 
(14) Folgering H. The hyperventilation syndrome. In: Altose MD, Kawakami Y, editors. Control of Breathing in Health and Disease. Part I. Physiological Foundations. Marcel Dekker Inc.; 1999. p. 633-60.

(15) Widmer S, Conway A, Cohen S, Davies P. Hyperventilation: A correlate and predictor of debilitating performance anxiety in musicians. Medical Problems of Performing Artists 1997;12(4):97-106.

(16) Spielberger C. Manual for the State-Trait Anxiety Inventory (Form Y). Palo Alto, CA: Consulting Psychologists Press; 1983.

(17) van Dixhoorn J, Duidenvoorden HJ. Efficacy of Nijmegen Questionnaire in Recognition of the Hyperventilation Syndrome. Journal of Psychosomatic Research 1985;29(2):199-206.

(18) van Doorn P, Colla P, Folgering H. Kort Rapport: Een vragenlijst voor hyperventilatieklachten. De Psycholoog 1983;18(10):573-7.

(19) Abel L, Larkin T. Anticipation of Performance among Musicians: Physiological Arousal, Confidence, and State-Anxiety. Psychology of Music 1990;18:171-82.

(20) Brashear RE. Hyperventilation Syndrome. Lung 1983;161(5):257-73.

(21) Lum LC. Hyperventilation: the tip and the iceberg. Journal of Psychosomatic Research $1975 ; 19: 375-83$.

(22) Studer R, Gomez P, Hildebrandt H, Arial M, Danuser B. Stage Fright: Its Experience as a Problem and Coping with it. International Archives of Occupational and Environmental Health (in press).

(23) Lehrer PM, Goldman NS, Strommen EF. A Principal Components Assessment of Performance Anxiety Among Musicians. Medical Problems of Performing Artists 1990;5(1):12-8.

(24) Linsky AS. Stimulating Responses to Mailed Questionnaires - Review. Public Opinion Quarterly 1975;39(1):82-101.

(25) Cox WJ, Kenardy J. Performance Anxiety, Social Phobia, and Setting Effects in Instrumental Music Students. Journal of Anxiety Disorders 1993 Jan;7(1):49-60.

(26) Fehm L, Schmidt K. Performance anxiety in gifted adolescent musicians. Journal of Anxiety Disorders 2006;20(1):98-109.

(27) Thomas M, McKinley RK, Freeman E, Foy C. Prevalence of dysfunctional breathing in patients treated for asthma in primary care: cross sectional survey. British Medical Journal 2001;322(7294):1098-100.

(28) Vansteenkiste J, Rochette F, Demedts M. Diagnostic-Tests of Hyperventilation Syndrome. European Respiratory Journal 1991;4(4):393-9.

(29) Schweitzer MB, Paulhan I. Manuel pour l'Inventaire d'Anxiété Trait-Etat (forme Y). Paris: Editions du Centre de Psychologie Appliquée; 1990. 
(30) Brodsky W. Music Performance Anxiety Reconceptualized: A Critique of Current Research Practices and Findings. Medical Problems of Performing Artists 1996;11:8898.

(31) Kim Y. Combined treatment of improvisation and desensitization to alleviate music performance anxiety in female college pianists: A pilot study. Medical Problems of Performing Artists 2005;20(1):17-24.

(32) Kokotsaki D, Davidson JW. Investigating Musical Performance Anxiety among Music College Singing Students: a quantitative analysis. Music Education Research 2003;5(1):45-59.

(33) Steptoe A, Malik F, Pay C, Pearson P, Price C, Win Z. The Impact of Stage Fright on Student Actors. British Journal of Psychology 1995;86:27-39.

(34) Laux L, Glanzmann P, Schaffner P, Spielberger CD. Das State-Trait-Angstinventar STAI: Theoretische Grundlagen und Handanweisung (State-Trait Anxiety Inventory: Theoretical foundations and instructions for application). Weinheim : Beltz; 1981.

(35) Nolenhoeksema S. Sex-Differences in Unipolar Depression - Evidence and Theory. Psychological Bulletin 1987;101(2):259-82.

(36) Grossman P, de Swart JCG. Diagnosis of Hyperventilation Syndrome on the Basis of Reported Complaints. Journal of Psychosomatic Research 1984;28(2):97-104.

(37) Gilbert C. Hyperventilation and the body. Accident \& Emergency Nursing 1999;7:130-40.

(38) van Kemenade JFLM, van Son MJM, van Heesch NCA. Performance Anxiety Among Professional Musicians In Symphonic Orchestras: A Self-Report Study. Psychological Reports 1995;77:555-62. 
Table 1 : Descriptive results for the NQ scores, the STAI-S score and the stage fright as a problem score

\begin{tabular}{|c|c|c|c|c|c|}
\hline & $\mathrm{n}$ & Mean & SD & Min & $\operatorname{Max}$ \\
\hline All & 169 & & & & \\
\hline NQ score WIDMER ET AL. (1997) & 141 & 18.89 & 9.17 & & \\
\hline NQ score & 169 & 19.50 & 8.72 & 0 & 47 \\
\hline STAI-S score WIDMER ET AL. (1997) & 141 & 45.07 & 12.25 & & \\
\hline STAI-S score & 169 & 46.83 & 10.76 & 25 & 75 \\
\hline SFP & 169 & 2.12 & 1.03 & 0 & 4 \\
\hline Men & 66 & & & & \\
\hline NQ score & 66 & 16.33 & 8.01 & 0 & 42 \\
\hline STAI-S score & 66 & 44.70 & 10.02 & 25 & 66 \\
\hline SFP & 66 & 1.97 & 1.11 & 0 & 4 \\
\hline Women & 103 & & & & \\
\hline NQ score & 103 & 21.52 & 8.59 & 4 & 47 \\
\hline STAI-S score & 103 & 48.19 & 11.03 & 25 & 75 \\
\hline SFP & 103 & 2.22 & 0.97 & 0 & 4 \\
\hline Wind musicians/singers & 68 & & & & \\
\hline NQ & 68 & 19.51 & 8.62 & 4 & 40 \\
\hline NQ_resp & 67 & 6.16 & 4.00 & 0 & 16 \\
\hline NQ_nonresp & 67 & 13.25 & 5.80 & 3 & 28 \\
\hline STAI-S score & 68 & 45.51 & 11.19 & 25 & 75 \\
\hline SFP & 68 & 2.03 & 1.01 & 0 & 4 \\
\hline Other musicians & 101 & & & & \\
\hline NQ & 101 & 19.49 & 8.34 & 0 & 47 \\
\hline NQ_resp & 99 & 4.77 & 3.62 & 0 & 15 \\
\hline NQ_nonresp & 99 & 14.72 & 6.57 & 0 & 35 \\
\hline STAI-S score & 101 & 47.71 & 10.42 & 25 & 74 \\
\hline SFP & 101 & 2.12 & 1.05 & 0 & 4 \\
\hline
\end{tabular}

$\mathrm{n}=$ number of observations; $\mathrm{SD}=$ standard deviation; $\mathrm{NQ}=$ Nijmegen Questionnaire; $\mathrm{SFP}=$ Stage Fright as a Problem; NQ_resp=respiratory subscale of the Nijmegen Questionnaire; NQ_nonresp=nonrespiratory subscale of the Nijmegen Questionnaire ; STAI-S=state scale of the Spielberger State-Trait Anxiety Inventory 
Table 2 : Correlations $(r)$ and explained variance $\left(r^{2}\right)$ between NQ and STAI-S scores, and between NQ and stage fright as a problem scores (SFP). Shown are the correlations of the complete samples (men and women) and separately by gender. For comparison, correlations from Widmer et al. (1997) are also reported.

\begin{tabular}{|c|c|c|c|}
\hline & & \multicolumn{2}{|c|}{ Correlations with NQ } \\
\hline & & STAI-S & SFP \\
\hline & & $r$ & $r$ \\
\hline & $\mathrm{n}$ & $\left(r^{2}\right)$ & $\left(r^{2}\right)$ \\
\hline \multicolumn{4}{|l|}{ All } \\
\hline Present sample & 169 & $\begin{array}{l}.45^{* * *} \\
(0.20)\end{array}$ & $\begin{array}{l}.47 * * * \\
(0.22)\end{array}$ \\
\hline Sample wIDMER ET AL. (1997) & 141 & $\begin{array}{l}.71 * * * \\
(0.50)\end{array}$ & \\
\hline \multicolumn{4}{|l|}{ Men } \\
\hline Present sample & 66 & $\begin{array}{l}.50 * * * \\
(0.25)\end{array}$ & $\begin{array}{l}.45^{* * *} \\
(0.20)\end{array}$ \\
\hline Sample wIDMER ET AL. (1997) & 56 & $\begin{array}{l}.52 * * * \\
(0.27)\end{array}$ & \\
\hline \multicolumn{4}{|l|}{ Women } \\
\hline Present sample & 103 & $\begin{array}{l}.40 * * * \\
(0.16)\end{array}$ & $\begin{array}{l}.45^{* * *} \\
(0.20)\end{array}$ \\
\hline Sample WIDMER ET AL. (1997) & 85 & $\begin{array}{l}.78 * * * \\
(0.61)\end{array}$ & \\
\hline
\end{tabular}

$* * * p<.001$

$\mathrm{n}=$ number of observations; $\mathrm{r}=$ Pearson correlation coefficient; NQ=Nijmegen Questionnaire; STAI-S= state scale of the Spielberger State-Trait Anxiety Inventory; SFP=Experience of Stage Fright as a Problem 
Table 3 : Correlations $(r)$ and explained variance $\left(r^{2}\right)$ between the NQ scores (total score and the two scores of the subscales) and both the STAI-S and the experience of stage fright as a problem (SFP) scores, separately by instrument type: wind musicians/singers $(n=68)$ and others $(n=101)$.

\begin{tabular}{lcc}
\hline & \multicolumn{2}{c}{ Instrument type } \\
\cline { 2 - 3 } & Wind musicians / & Others \\
& Singers & $r$ \\
& $\left(r^{2}\right)$ & $\left(r^{2}\right)$ \\
\hline NQ - STAI-S & $.41^{* * *}$ & $.49^{* * *}$ \\
& $(.17)$ & $(.24)$ \\
NQ_resp - STAI-S & $.29^{*}$ & $.37 * * *$ \\
& $(.08)$ & $(.14)$ \\
NQ_nonresp - STAI-S & $.46^{* * *}$ & $.46^{* * *}$ \\
& $(.21)$ & $(.21)$ \\
NQ - SFP & & \\
& $.40^{* * *}$ & $.50^{* * *}$ \\
NQ_resp - SFP & $(.16)$ & $(.25)$ \\
& $.25^{*}$ & $.43^{* * *}$ \\
NQ_nonresp - SFP & $(.06)$ & $(.18)$ \\
& $.43^{* * *}$ & $.44^{* * *}$ \\
$* * * p<001 ; * p<05$ & $(.18)$ & $(.19)$
\end{tabular}

$* * * p<.001 ; * p<.05$

$\mathrm{r}=$ Pearson correlation coefficient; $\mathrm{NQ}=$ Nijmegen Questionnaire; NQ_resp=respiratory subscale of the Nijmegen Questionnaire ; NQ_nonresp=non-respiratory subscale of the Nijmegen Questionnaire;

STAI-S= state scale of the Spielberger State-Trait Anxiety Inventory; SFP=Experience of Stage Fright as a Problem 
Figure 1: Scatter plot of the NQ scores and the STAI-S scores with the linear prediction line ( $\mathrm{n}=169)$ Figure 2: Scatter plot of the NQ scores and the stage fright as a problem scores with the linear prediction line $(\mathrm{n}=169)$ 


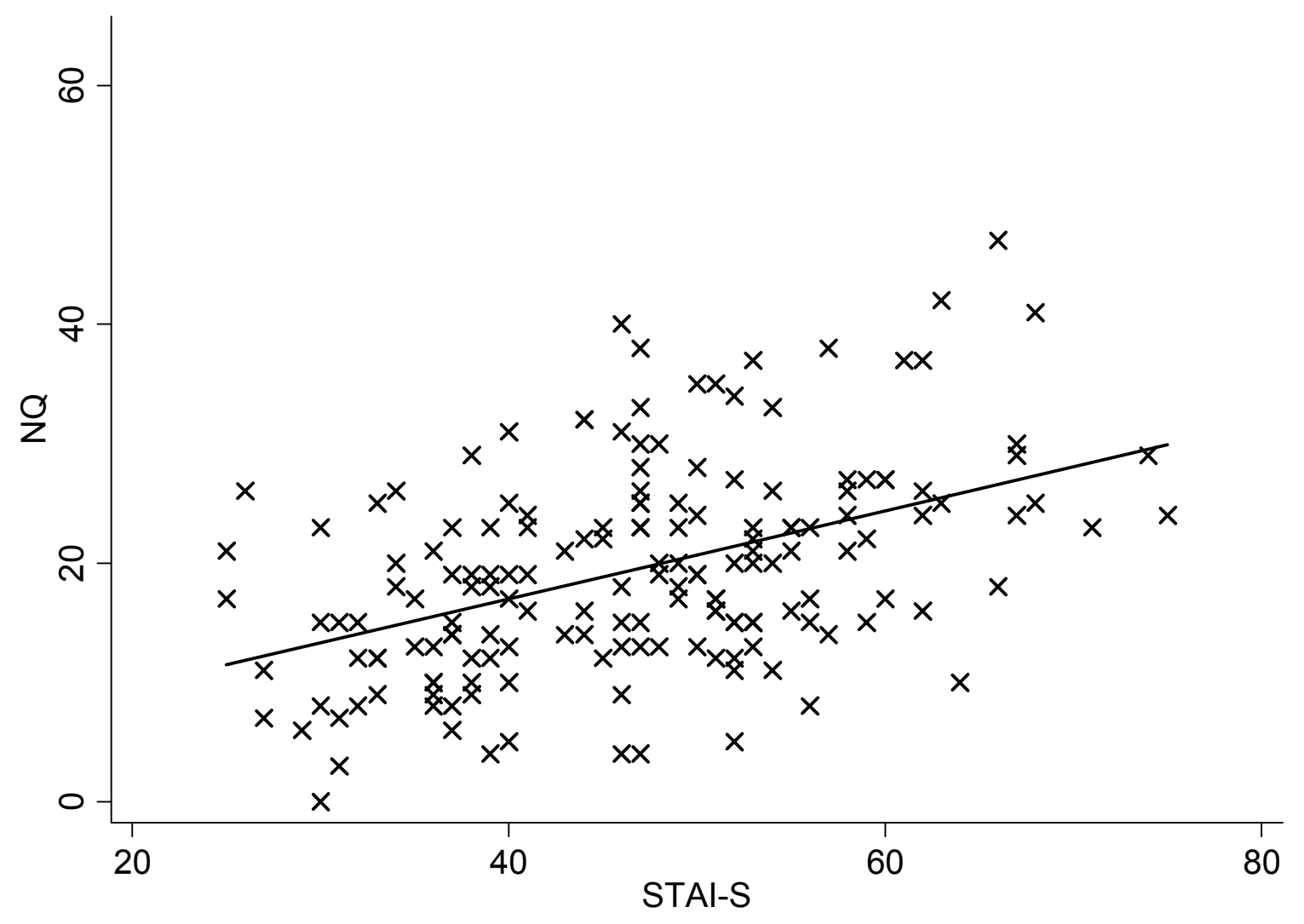

Figure 1 


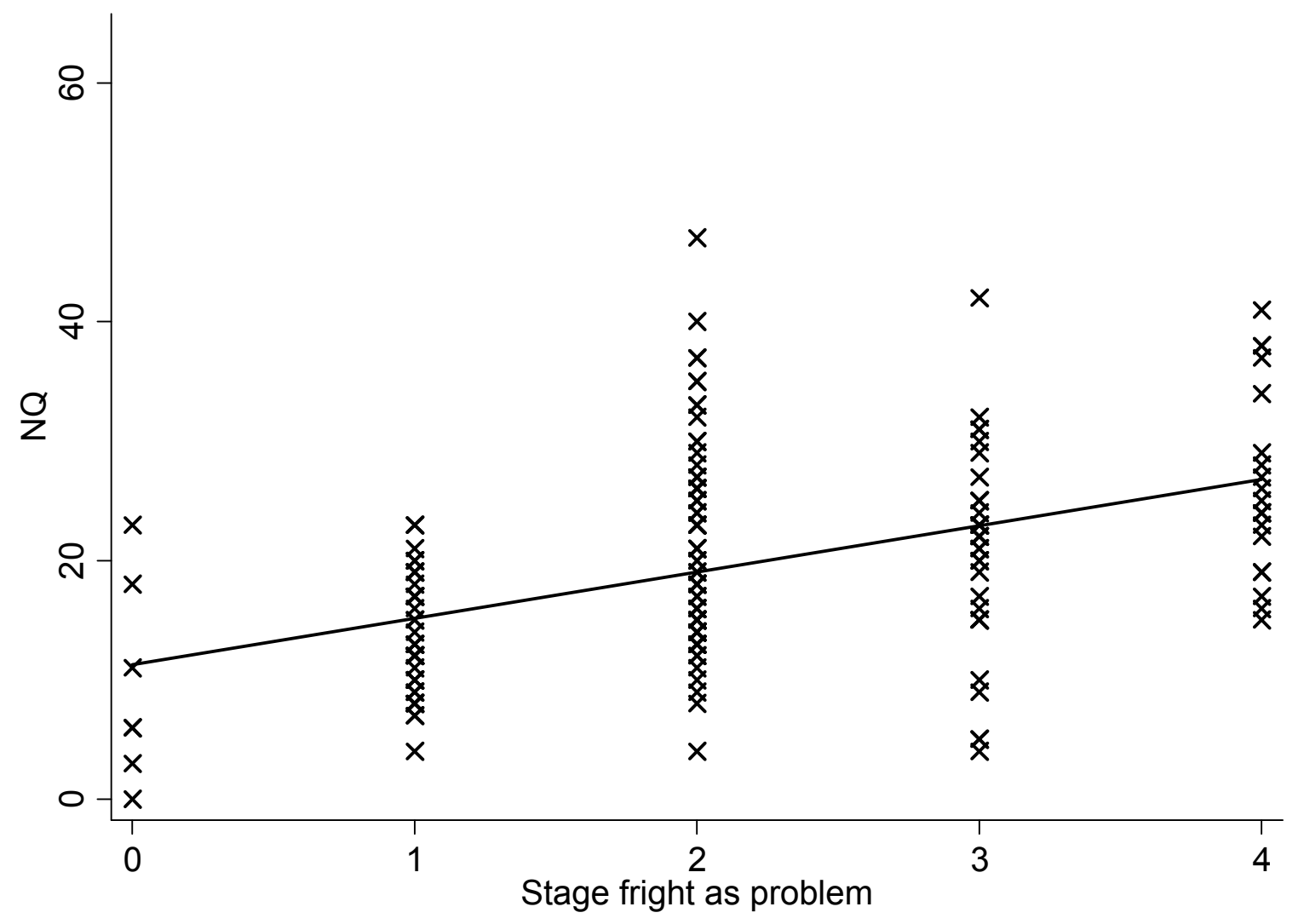

Figure 2 